\title{
Direct Power Control of Three-Phase Boost Rectifiers by using a Sliding-Mode Scheme
}

\author{
Ju-Hye Kim*, Sung-Tak Jou*, Dae-Keun Choi ${ }^{*}$, and Kyo-Beum Lee ${ }^{\dagger}$ \\ ${ }^{*}$ Dept. of Electrical and Computer Engineering, Ajou University, Suwon, Korea
}

\begin{abstract}
This paper proposes a sliding-mode-based direct power control (DPC) method in a three-phase boost rectifier without the use of a voltage sensor. This sliding-mode-based DPC is used to improve transient-state response characteristics. This DPC can eliminate voltage sensors by calculating a voltage using a sensorless method, thus considerably reducing cost. This DPC first presents an effective algorithm that does not significantly affect the previous performance and does not need a voltage sensor. Thereafter, the effectiveness of the algorithm is verified by simulations and experiments.
\end{abstract}

Key words: Direct power control (DPC), Sensorless control, Sliding-mode controller, Three-phase boost rectifier

\section{INTRODUCTION}

A three-phase boost rectifier is widely used in obtaining DC outputs from three-phase power systems and in linking renewable energy outputs to the grid [1]. This rectifier can be applied in many fields such as battery charging systems and can be used in the inspection devices of inverters in electric vehicles.

A three-phase boost rectifier enables control by using a system that converts the $\mathrm{AC}$ voltage source to the $\mathrm{DC}$ output by direct power control (DPC), which is an instantaneous active and reactive power control [2]. Although DPC has an excellent response speed by using the hysteresis controller, DPC has difficulty in unstable states because of variable phenomena resulting from switching frequencies.

To complement the switching frequency variable phenomena, DPC is used in conjunction with space vector modulation (SVM) [3]-[5]. The SVM method compensates for the variation of frequency. However, the SVM method has difficulties in reducing the response speed. To resolve this problem, we used a sliding-mode controller (SMC).

SMCs, which are type of variable structure controller, are nonlinear controllers that determine the sliding plane during the structural change of a control system. SMC is a control method that is necessary in improving transient-state response

Manuscript received May 3, 2013; revised Jul. 29, 2013

Recommended for publication by Associate Editor Yong Kang.

†Corresponding Author: kyl@ajou.ac.kr

Tel: +82-31-219-2376, Fax: +81-31-212-9531, Ajou University

*Dept. of Electrical and Computer Engineering, Ajou University, Korea characteristics [6]-[8].

This paper proposes the sliding-mode based DPC method, which allows control without the use of voltage sensors. The proposed method reduces cost and achieves a fast response by stabilizing the system with the gains of the PI controller of a linear structure and the gains of the sliding mode of a variable structure.

The proposed method focuses on the SMC, which offers the compensation method with response speed, and the relation between the virtual flux and power. A PI controller exhibits a constant gain regardless of the size of the grid voltage but has a drawback, namely, the slow response of the current output in maintaining the output power during in grid voltage variations [9]. To maintain the excellent response characteristics of the $\mathrm{DPC}$, an SMC with a variable gain is required. When using the SMC, unlike the PI controller, the dynamic response characteristic of the output current for maintaining the output power is significantly improved [10].

This controller is designed to improve the performance of the DC power supply system for electric vehicle inverter diagnosis systems. Simulations and experimental results are presented to verify the performance of the proposed SMC.

\section{Design OF SLIDING-Mode CONTROLLER}

\section{A. System Configuration and Sliding-Mode Control}

Fig. 1 shows the system of a three-phase boost rectifier. A three-phase boost rectifier consists of a power converter to transfer the three-phase voltages to the DC-link voltage. Moreover, $i_{a,}, i_{b}$, and $i_{c}$ represent the currents of each phase. 


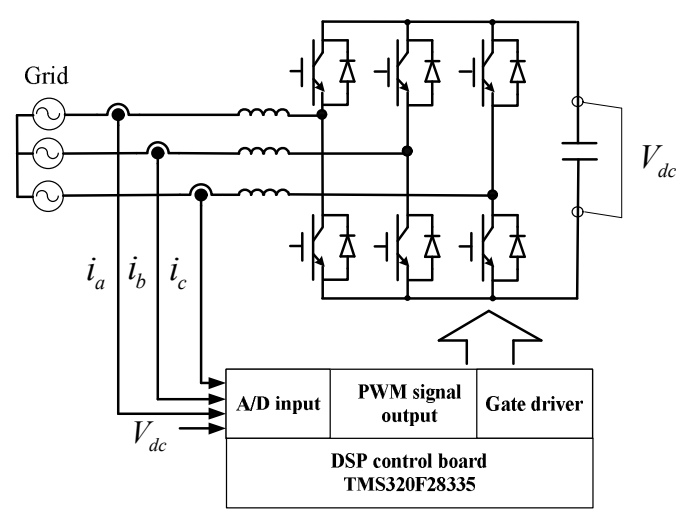

Fig. 1. Configuration of the three-phase boost rectifier system.

Power and DC-link voltage controls are performed efficiently in the three-phase boost rectifier [11].

This paper uses DPC-SVM to improve the variation of switching frequency. To have a better response speed, we use the SMC.

The error between power and the power reference value is expressed as follows:

$$
\begin{aligned}
& e_{P s}=P_{P s}-P_{P s}^{*} \\
& e_{Q s}=Q_{Q s}-Q_{Q s}^{*} .
\end{aligned}
$$

Sliding-mode planes are expressed by the Laplace equation as follows [12]:

$$
\begin{aligned}
& S_{P s}=e_{P s}+k_{a} s e_{P s} \\
& S_{Q s}=e_{Q s}+k_{b} s e_{Q s}
\end{aligned},
$$

where $k_{a}$ and $k_{b}$ signify the sliding surface constants.

Sliding-mode planes consist of the sum of the error between the power and power reference value, as well as and the error of the differential value (Equation (2)).

When the sliding plane and differential value become zero, the error value of the reference power and the actual power converge to the sliding plane [13].

$$
\begin{aligned}
& G_{P}=e_{P_{s}}+K_{V S P} \operatorname{sat}\left(e_{P_{s}} S_{P_{s}}\right) \\
& G_{Q}=e_{Q_{s}}+K_{V S Q} \operatorname{sat}\left(e_{Q_{s}} S_{Q_{s}}\right) .
\end{aligned}
$$

$K_{V S P}$ and $K_{V S Q}$ represent the gain of the variable structure control (VSC). The control input proposed in Equation (3) is an applied form that comprises the control input of the variable structure and control input of the linear structure.

To improve the response speed, the control input is determined by multiplying the error value and function.

This method can use a stable and fast variable gain to improve the transient-state response characteristics and controller performance by compensating for the chattering phenomenon promptly. This method demonstrates the benefit of fast dynamic characteristics, which are also exhibited by the DPC.

By using the control input (Fig. 2), the reference voltage of

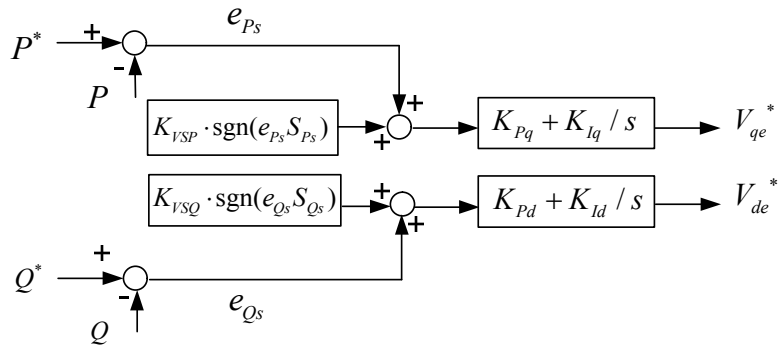

Fig. 2. Reference voltages.

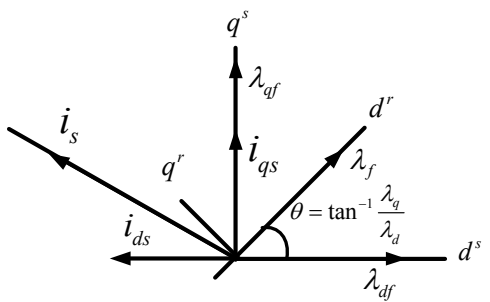

Fig. 3. Three-phase boost rectifier system as an imaginary AC motor.

switching can be shown as follows:

$$
\begin{aligned}
V_{q e} & =\left(K_{P q}+K_{I q} / s\right) G_{P} \\
& =\left(K_{P q}+K_{I q} / s\right)\left\{e_{P s}+K_{V S P} \operatorname{sat}\left(e_{P s} S_{P s}\right)\right\} . \\
V_{d e} & =\left(K_{P d}+K_{I d} / s\right) G_{Q} \\
& =\left(K_{P d}+K_{I d} / s\right)\left\{e_{Q s}+K_{V S Q} \operatorname{sat}\left(e_{Q s} S_{Q s}\right)\right\}
\end{aligned}
$$

where $K_{P q}, K_{I q}, K_{P d}$, and $K_{I d}$ are the gains of the PI controller.

The SMC has the advantage of having active and reactive powers with fast response speeds; however, the unstable chattering phenomenon still occurs because of fast switching. To improve this condition, the following functions are applied:

In Equation (5), $\alpha_{d}$ and $\alpha_{q}$ are the constants of the functions that are applied to the active and reactive powers, respectively. By deciding the adequate constant, the chattering phenomenon can be compensated [14].

$$
\begin{aligned}
& \operatorname{sat}\left(e_{P_{s}} S_{P s}\right)=\left\{\begin{array}{cc}
1 & e_{P s} S_{P_{s}}>\alpha_{d} \\
e_{P S} S_{P s} / \alpha_{d} & \left|e_{P_{s}} S_{P_{s}}\right| \leq \alpha_{d} \\
-1 & e_{P_{s}} S_{P_{s}}<-\alpha_{d}
\end{array}\right. \\
& \operatorname{sat}\left(e_{Q S} S_{Q_{s}}\right)=\left\{\begin{array}{cc}
1 & e_{Q s} S_{Q_{s}}>\alpha_{q} \\
e_{Q s} S_{Q_{s}} / \alpha_{q} & \left|e_{Q s} S_{Q_{s}}\right| \leq \alpha_{q} \\
-1 & e_{Q s} S_{Q s}<-\alpha_{q}
\end{array}\right. \\
& \alpha_{d}>0, \alpha_{q}>0
\end{aligned}
$$

\section{B. Stability Analysis of SMC}

The output reference voltage can be expressed as Equation (4). The output power obtained from the output reference voltage is expressed as follows: 


$$
\begin{aligned}
P_{P s} & =\frac{-E_{g}}{L s+R}\left(K_{P q}+K_{I q} / s\right) G_{P} \\
& =\frac{-E_{g}}{L s+R}\left(K_{P q}+K_{I q} / s\right)\left\{e_{P s}+k_{a} \operatorname{sat}\left(e_{P s} S_{P s}\right)\right\} \\
& =\frac{m_{p} s+n_{p}}{s^{2}+\left(R / L+m_{p}\right) s+n_{p}}\left\{P_{P s}^{*}-k_{a} \operatorname{sat}\left(e_{P s} S_{P s}\right)\right\} \\
Q_{Q s} & =\frac{-E_{g}}{L s+R}\left(K_{P d}+K_{I d} / s\right) G_{Q} \\
& =\frac{-E_{g}}{L s+R}\left(K_{P d}+K_{I d} / s\right)\left\{e_{Q s}+k_{b} \operatorname{sat}\left(e_{Q s} S_{Q s}\right)\right\} \\
& =\frac{m_{q} s+n_{q}}{s^{2}+\left(R / L+m_{q}\right) s+n_{q}}\left\{Q_{Q s}^{*}-k_{b} \operatorname{sat}\left(e_{Q s} S_{Q s}\right)\right\}
\end{aligned}
$$

where $m_{p}=K_{P q} E_{g} / L, n_{p}=K_{I q} E_{g} / L$.

$$
m_{q}=K_{P d} E_{g} / L, n_{q}=K_{I d} E_{g} / L \text {. }
$$

The error values of the active and reactive powers for determining the stability can be rearranged as follows:

$$
\begin{aligned}
& e_{1}=e_{P_{s}}, e_{2}=\dot{e_{P s}} \\
& \dot{e_{2}}=m_{p} e_{2}-n_{p} e_{1}-\frac{R}{L} \dot{P_{P s}}-n_{p} k_{a} \operatorname{sat}\left(e_{P_{s}} S_{P_{s}}\right)-\ddot{P_{P s}^{*}} \\
& e_{3}=e_{P_{s}}, e_{4}=\dot{e_{Q s}} \\
& \dot{e_{4}}=m_{q} e_{2}-n_{q} e_{1}-\frac{R}{L} \dot{Q_{Q s}}-n_{q} k_{b} \operatorname{sat}\left(e_{Q s} S_{Q_{s}}\right)-\ddot{Q_{Q s}^{*}} .
\end{aligned}
$$

Equation (8) shows the error value multiplied to the sliding plane for determining the stability of the chosen control input:

$$
S_{P s 1}=e_{P s}^{2}+k_{a} e_{P s} s e_{P s}, S_{Q s 1}=e_{Q s}^{2}+k_{b} e_{Q s} s e_{Q s} .
$$

To find the gain value for stabilizing the system, the Lyapunov function is used. The function is determined by $V_{P}=S_{P s 1}^{2} / 2$ and $V_{Q}=S_{Q s 1}^{2} / 2$, and the equation for determining the control gain can be expressed as follows:

$$
\begin{aligned}
\dot{V}_{P}=\dot{S_{P s 1}} S_{P s 1}= & -k_{a} n_{p} S_{P s 1}^{2}-k_{a} n_{p} e_{1} K_{V S P}\left|S_{P s 1}\right| \\
& -\left\{k_{a}\left(\frac{R}{L} \dot{P_{P s}}-k_{a} n_{p} e_{2}-m_{p} e_{2}\right) e_{1}-\left(1+k_{a}\right) e_{2}^{2}\right\} S_{P_{s 1}}, \\
= & -k_{a} n_{p} S_{P s 1}^{2}-H_{P}\left|S_{P s 1}\right| \\
\dot{V_{Q}}=\dot{S}_{Q s 1} S_{Q s 1}= & -k_{b} n_{Q} S_{Q s 1}^{2}-k_{b} n_{Q} e_{3} K_{V S Q}\left|S_{Q s 1}\right| \\
& -\left\{k_{b}\left(\frac{R}{L} \dot{Q_{Q s}}-k_{b} n_{Q} e_{4}-m_{Q} e_{4}\right) e_{3}-\left(1+k_{b}\right) e_{4}^{2}\right\} S_{Q s 1} \\
= & -k_{b} n_{Q} S_{Q s 1}^{2}-H_{Q}\left|S_{Q s 1}\right|
\end{aligned}
$$

where

$$
\begin{aligned}
& H_{P}=\left|k_{a}\left(\frac{R}{L} \dot{P_{P s}}-k_{a} n_{p} e_{2}-m_{p} e_{2}\right) e_{1}-\left(1+k_{a}\right) e_{2}^{2}\right|+k_{a} n_{p} e_{1} K_{V S P}, \\
& H_{Q}=\left|k_{b}\left(\frac{R}{L} \dot{Q_{Q s}}-k_{b} n_{Q} e_{4}-m_{Q} e_{4}\right) e_{3}-\left(1+k_{b}\right) e_{4}^{2}\right|+k_{b} n_{Q} e_{3} K_{V S Q} .
\end{aligned}
$$

At this instance, when $\dot{V}_{P}<0$ and $\dot{V}_{Q}<0$, the stable variable gain value of the active and reactive powers can be expressed as follows:

$$
\begin{aligned}
& K_{V S P} \geq\left|k_{a}\left(\frac{R}{L} \dot{P_{P s}}-k_{a} n_{p} e_{2}-m_{p} e_{2}\right) e_{1}-\left(1+k_{a}\right) e_{2}^{2}\right| /\left(k_{a} n_{p} e_{1}\right) . \\
& K_{V S Q} \geq\left|k_{b}\left(\frac{R}{L} \dot{Q_{Q s}}-k_{b} n_{Q} e_{4}-m_{Q} e_{4}\right) e_{3}-\left(1+k_{b}\right) e_{4}^{2}\right| /\left(k_{b} n_{Q} e_{3}\right) .
\end{aligned}
$$

\section{ThreE-Phase BoOst ReCTIFIER SyStem WITHOUT VOLTAGE SENSOR}

\section{A. Voltage Estimation}

The general methods obtained by the values of the active and reactive powers by using the relationship between the voltage and current transformed to the $\mathrm{d}-\mathrm{q}$ axis stationary reference frame are expressed as follows [15]:

$$
P=\frac{3}{2}\left(i_{d s} V_{d s}+i_{q s} V_{q s}\right), \quad Q=\frac{3}{2}\left(i_{d s} V_{q s}-i_{q s} V_{d s}\right) .
$$

The estimation of the voltage without the voltage sensor can be expressed by using the following voltage equation:

$$
\hat{E}_{s}=L \frac{d i_{s}}{d t}+V_{s},
$$

where $V_{s}$ denotes the output voltage generated in the direct power controller.

The voltage is the sum of the differential values of the current and output voltage.

\section{B. Power Estimation}

To estimate the active and reactive powers, we can create a virtual flux, which is given by the relationship between the voltage and flux [15]:

$$
\lambda_{s}=\int \hat{E}_{s} d t
$$

The virtual flux can be obtained by integrating the voltage. The d-q axis flux applied to this equation is expressed as follows:

$$
\lambda_{d}=\int E_{d f} d t, \lambda_{q}=\int E_{q f} d t .
$$

To estimate the power and produce the necessary currents, the d-q axis currents are applied. This method is expressed as follows:

$$
i_{d s}=\frac{\sqrt{6}}{3} i_{a}-\frac{\sqrt{6}}{6} i_{b}-\frac{\sqrt{6}}{6} i_{c}, i_{q s}=\frac{\sqrt{2}}{2} i_{b}-\frac{\sqrt{2}}{2} i_{c},
$$

where $i_{a}, i_{b}$, and $i_{c}$ denote the currents of each phase, and $i_{d s}$, and $i_{q s}$ denote the $\mathrm{d}-\mathrm{q}$ axis currents.

The estimated power equations by using the obtained voltage and current are given by the following:

$$
P=\operatorname{Re}\left(E_{s}, i_{s}^{*}\right), Q=\operatorname{Im}\left(E_{s}, i_{s}^{*}\right),
$$

where $i_{s}^{*}$ denotes the conjugate line current vector.

The estimated voltage shows the equations related to the flux and is expressed as follows: 


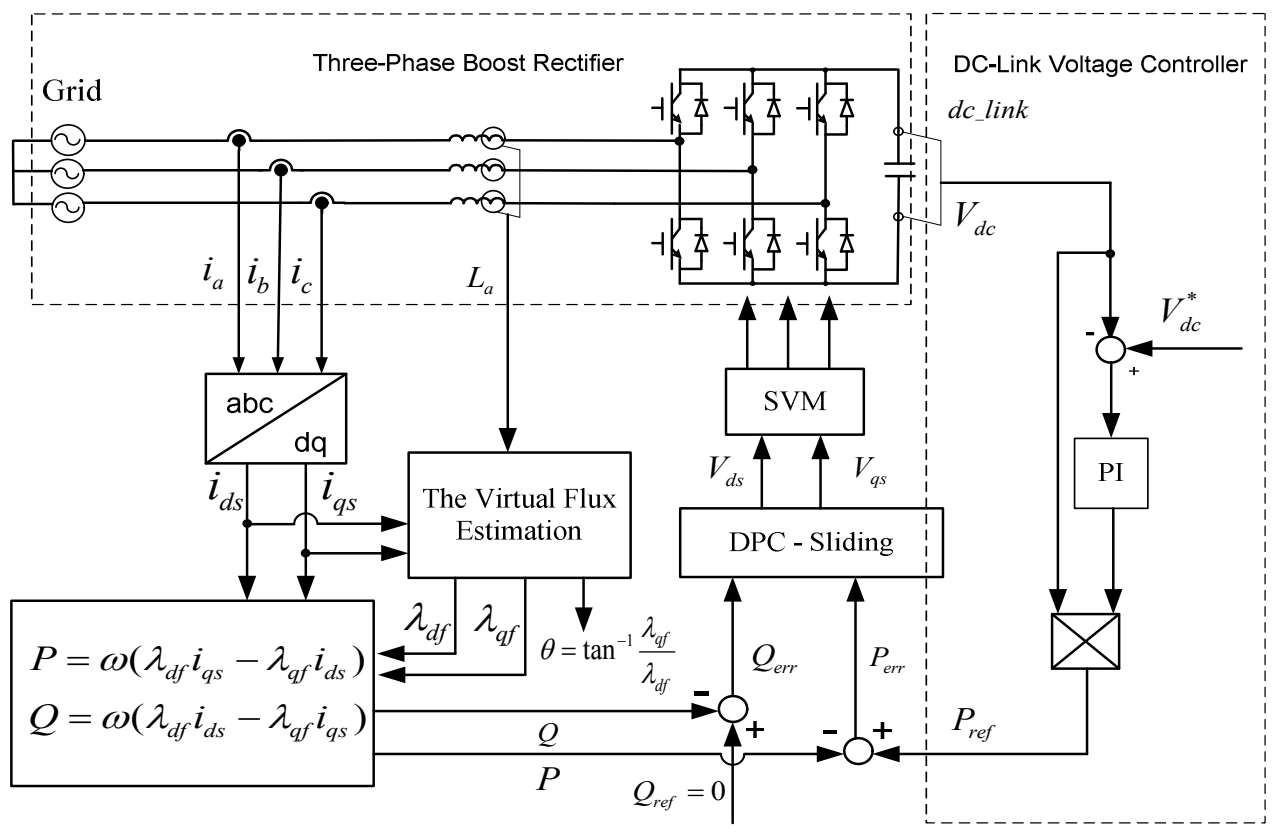

Fig. 4. Control block ofDPC.

TABLE I

SYSTEM PARAMETERS

\begin{tabular}{|c|c|c|c|}
\hline Parameter & Value & Parameter & Value \\
\hline \hline Switching period & $200[\mu \mathrm{s}]$ & $\begin{array}{c}\text { Inductance of } \\
\text { reactors }\end{array}$ & $4[\mathrm{mH}]$ \\
\hline Sampling period & $100[\mu \mathrm{s}]$ & dc-link voltage & $700[\mathrm{~V}]$ \\
\hline
\end{tabular}

$$
\begin{aligned}
\hat{E}_{s} & =\frac{d \lambda_{a}}{d t} e^{j \omega t}+j \omega \lambda_{a} e^{j \omega t}=\frac{d \lambda_{a}}{d t} e^{j \omega t}+j \omega \lambda_{f}, \\
& =\left.\frac{d \lambda_{a}}{d t}\right|_{d}+\left.j \frac{d \lambda_{a}}{d t}\right|_{q}+j \omega\left(\lambda_{d f}-j \lambda_{q f}\right)
\end{aligned}
$$

where $\lambda_{a}$ denotes the magnitude of a virtual flux.

The power is estimated by using Equations (16) and (17).

$$
\hat{E}_{s} i_{s}^{*}=\left\{\left.\frac{d \lambda_{a}}{d t}\right|_{d}+\left.j \frac{d \lambda_{a}}{d t}\right|_{q}+j \omega\left(\lambda_{d f}-j \lambda_{q f}\right)\right\}\left(i_{d s}-j i_{q s}\right) .
$$

The estimated active and reactive powers represent the equations that are divided into the real and imaginary parts related to the flux:

$$
\begin{aligned}
& P=\left.\frac{d \lambda_{f}}{d t}\right|_{d} i_{d s}+\left.\frac{d \lambda_{f}}{d t}\right|_{q} i_{q s}+\omega\left(\lambda_{d f} i_{q s}-\lambda_{q f} i_{d s}\right) \\
& Q=-\left.\frac{d \lambda_{f}}{d t}\right|_{d} i_{q s}+\left.\frac{d \lambda_{f}}{d t}\right|_{q} i_{d s}+\omega\left(\lambda_{d f} i_{d s}-\lambda_{q f} i_{q s}\right) .
\end{aligned}
$$

When Equation (20) is replaced by Equation (19), the active and reactive powers can be simplified into the equations composed of the flux and current:

$$
\begin{aligned}
& P=\omega\left(\lambda_{d f} i_{q s}-\lambda_{q f} i_{d s}\right) \\
& Q=\omega\left(\lambda_{d f} i_{d s}-\lambda_{q f} i_{q s}\right) .
\end{aligned}
$$
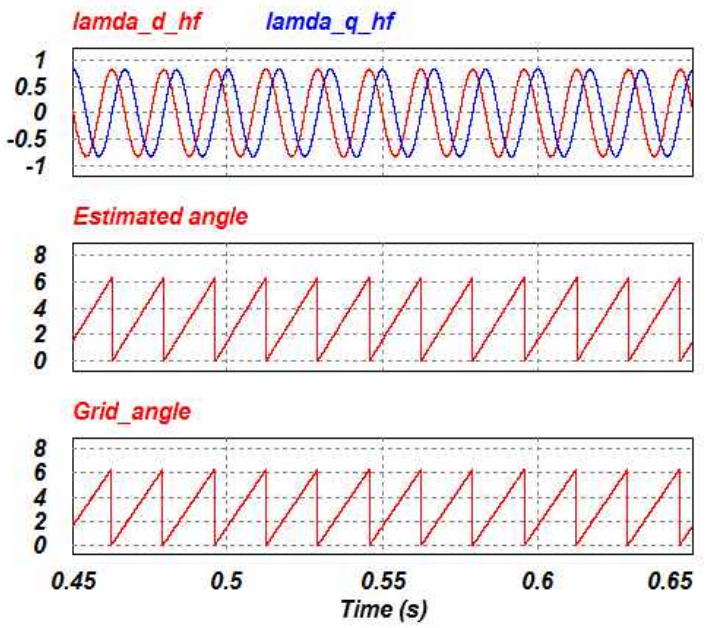

Fig. 5. (a) Virtual flux of d q-axis, (b) virtual flux angle, and (c) grid angle.

Fig. 4 shows the control block of DPC. The three-phase currents are transformed into d-axis and q-axis currents. Thereafter, the virtual flux is produced to derive the power calculation equation.

The DPC is the method wherein the active and apparent powers are instantaneously controlled and the difference in the value between the actual power and reference power is used as the input of the controller.

The output voltage of the controller becomes the reference voltage of switching. After the output voltage is transformed into the three phase voltages, the output voltage performs switching by using the space-vector pulse-width modulation. 


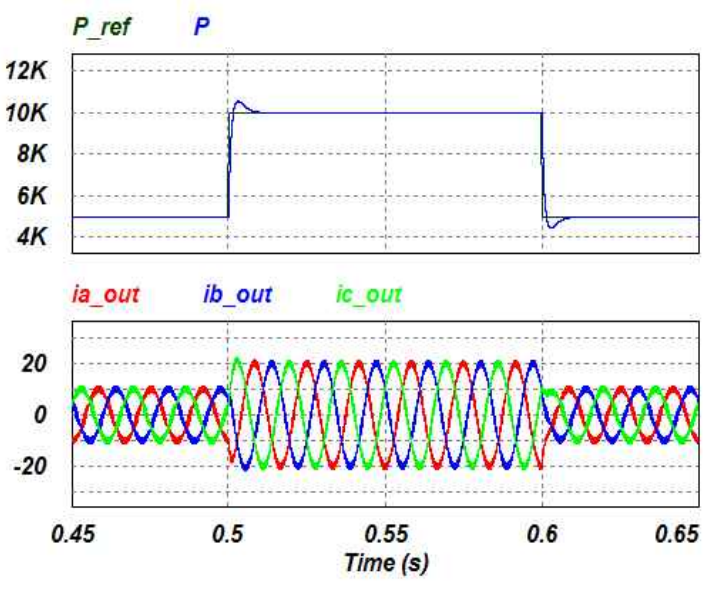

Fig. 6. Active power control by using a PI controller (overall view): (a) active power control and (b) grid currents.

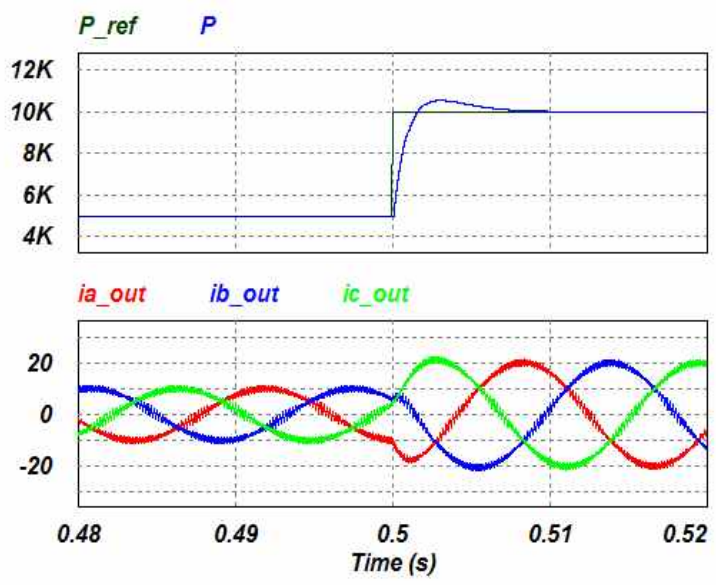

Fig. 7. Active power control by using a PI controller (zoomed-in at $0.5 \mathrm{~s}$ ): (a) active power control and (b) grid currents.

\section{Simulation}

The switching frequency is set to $5 \mathrm{kHz}$, and the DC-link voltage is set to $700 \mathrm{~V}$ (Table I). The bandwidth applied to the actual power calculation is $500 \mathrm{rad}$. The bandwidth of the PI controller gain value is $4000 \mathrm{rad}$, and the VSC gains are 800 each. We used PSIM to simulate the algorithms.

Figs. 6 and 8 are the waveforms performed by the DPC without voltage sensors. The reference active power is maintained at $5 \mathrm{~kW}$, increased to $10 \mathrm{~kW}$ at $0.5 \mathrm{~s}$, and then decreased to $5 \mathrm{~kW}$ at $0.6 \mathrm{~s}$. Fig. 6 only shows the conventional PI controller. The waveform below shows the grid current waveform when being controlled. The current is increased and decreased according to the reference power. Fig. 7 shows the zoomed-in images of the waveforms at $0.5 \mathrm{~s}$. The reference active power is maintained at $5 \mathrm{~kW}$ and then increases to $10 \mathrm{~kW}$ at $0.5 \mathrm{~s}$. The transient-state response characteristics can be closely observed.

Fig. 8 shows the method for improving the response speed by adding the SMC. The waveform below shows the grid

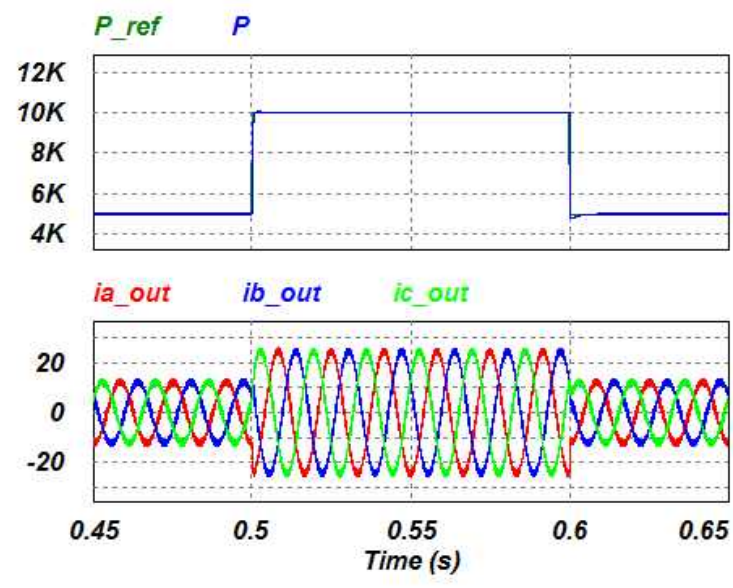

Fig. 8. Active power control by using a sliding mode (overall view): (a) active power control and (b) grid currents.

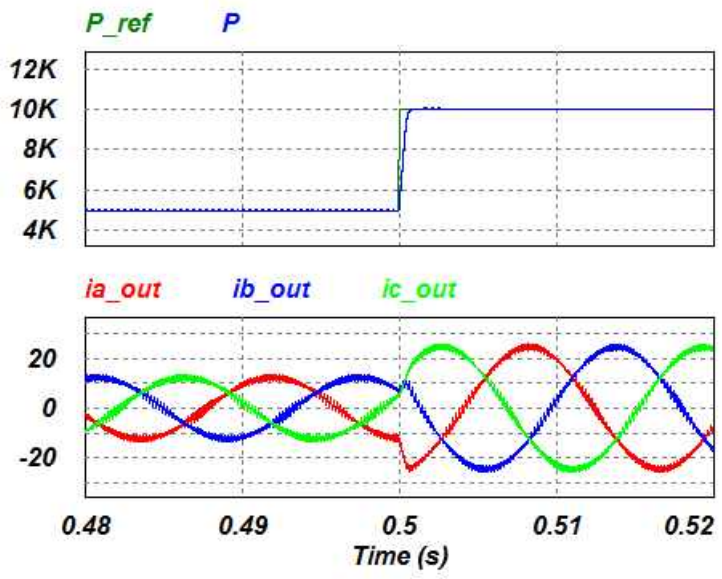

Fig. 9. Active power control by using a sliding mode (zoomed in at $0.5 \mathrm{~s}$ ): (a) active power control and (b) grid currents.

current waveform when being controlled. The current is increased and decreased according to the reference power. We conducted the control by changing the reference active power. We then verify the enhancement of the response speed by comparing the results shown in Fig. 6.

Fig. 9 shows the zoomed-in images of the waveforms at $0.5 \mathrm{~s}$. The reference active power is maintained at $5 \mathrm{~kW}$ and increases to $10 \mathrm{~kW}$ at $0.5 \mathrm{~s}$. The improved transient-state response characteristics can be closely observed.

\section{EXPERIMENTAL RESULTS}

The experiments are performed by using the experimental equipment (Fig. 10). This equipment is an experimental set for the inspection devices of inverters in electric vehicles. The proposed method was programmed on a TMS320F28335 digital signal processor. The experiment conditions are performed under the same conditions as the simulation. 


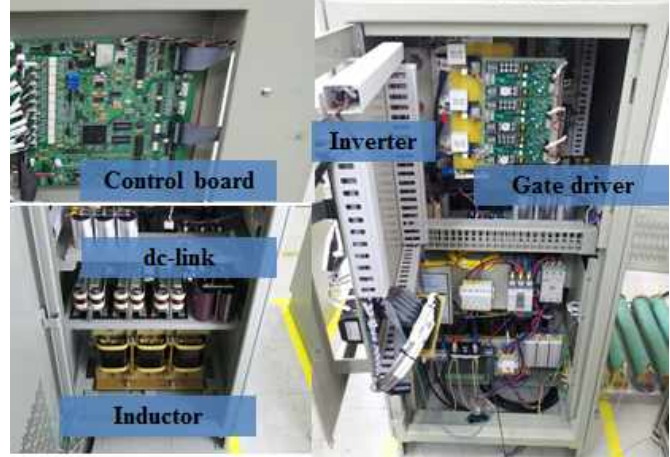

Fig. 10. Experimental equipment $(40 \mathrm{~kW})$.

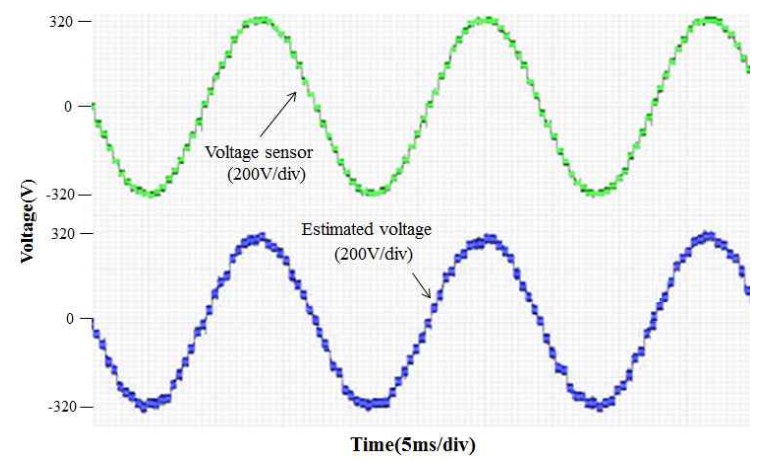

Fig. 11. Voltage of d-axis: (a) voltage sensor and (b) estimated voltage.

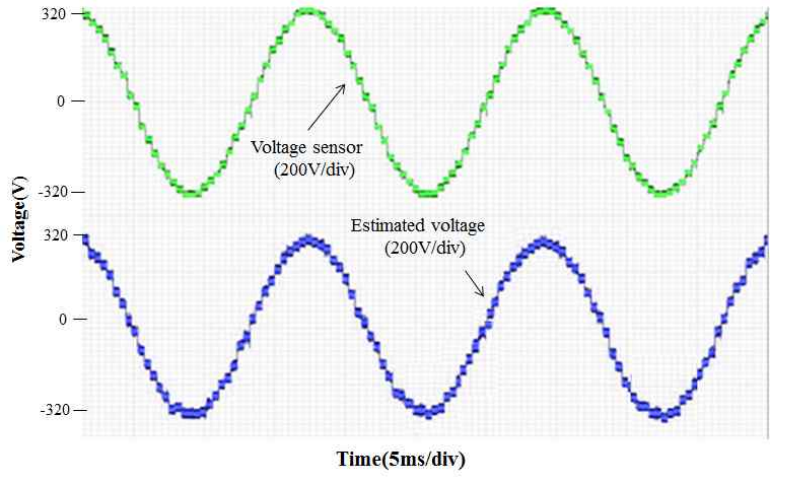

Fig. 12. Voltage of q-axis: (a) voltage sensor and (b) estimated voltage.

Figs. 11 and 12 show the waveforms of the $\mathrm{d}-\mathrm{q}$ axis voltages. These waveforms are viewed through the oscilloscope by the digital-to-analog function. The voltage value from the voltage sensor is similar to the estimated voltage.

Fig. 13 shows the waveforms presented as a virtual flux of the $\mathrm{d}-\mathrm{q}$ axis. The flux angle, which is identical to the grid angle, is obtained by a virtual flux. A comparison between the waveforms of the grid angle and estimated angle is shown in Fig. 14

Figs. 15 to 17 show the waveforms performed by the DPC without voltage sensors. Fig. 15 only uses the conventional PI controller. The reference active power is maintained at $5 \mathrm{~kW}$, increased to $15 \mathrm{~kW}$, and then decreased to $5 \mathrm{~kW}$. The

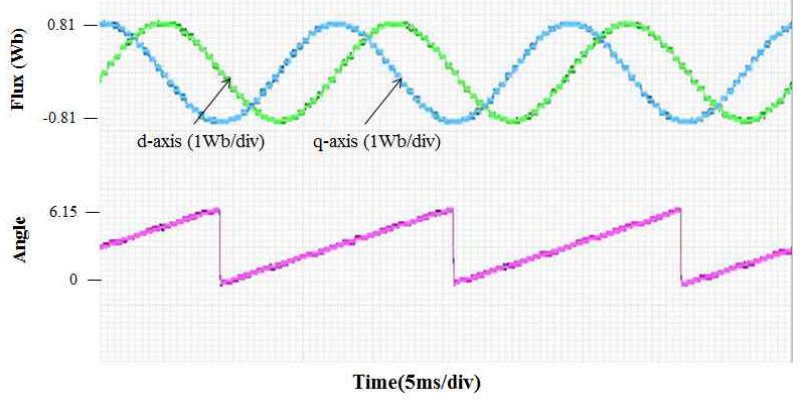

Fig. 13. (a) Virtual flux of the d q-axis and (b) virtual flux angle.

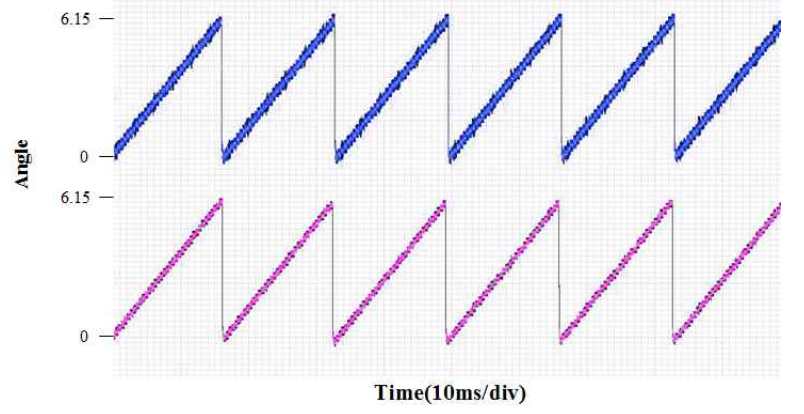

Fig. 14. (a) Grid angle and (b) virtual flux angle.

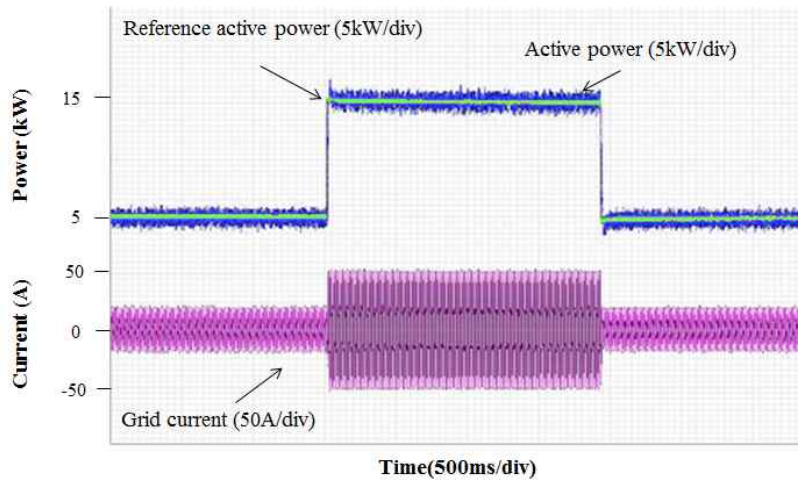

Fig. 15. Active power control by using a PI controller (overall view): (a) active power control and (b) grid currents.

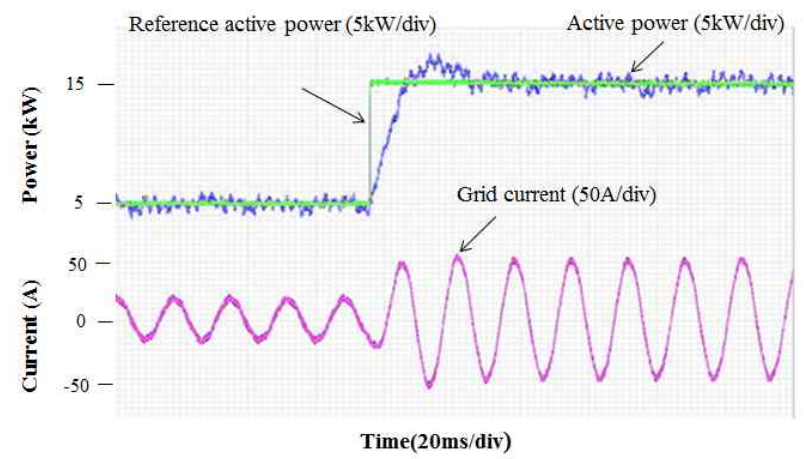

Fig. 16. Active power control by using a PI controller: (a) active power control and (b) grid current.

reference active power is exhibited as a grid current waveform when under control. Fig. 17 shows the method for improving the response speed by adding the SMC. 


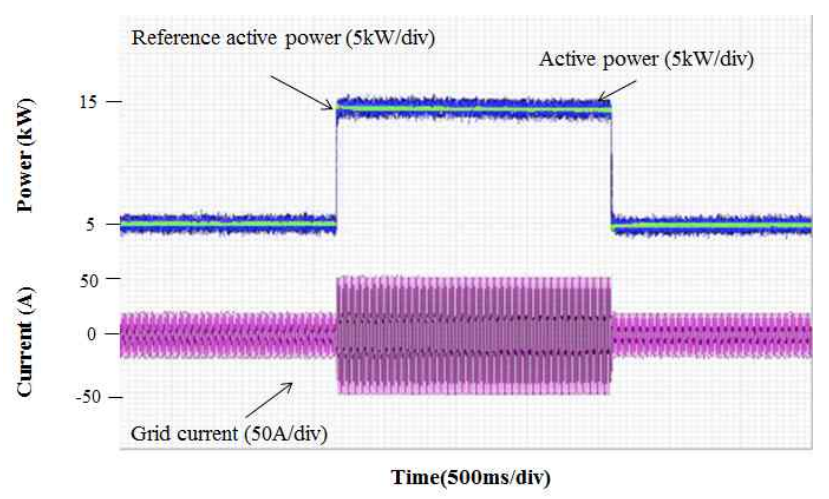

Fig. 17. Active power control by using a sliding mode (overall view): (a) active power control and (b) grid currents.

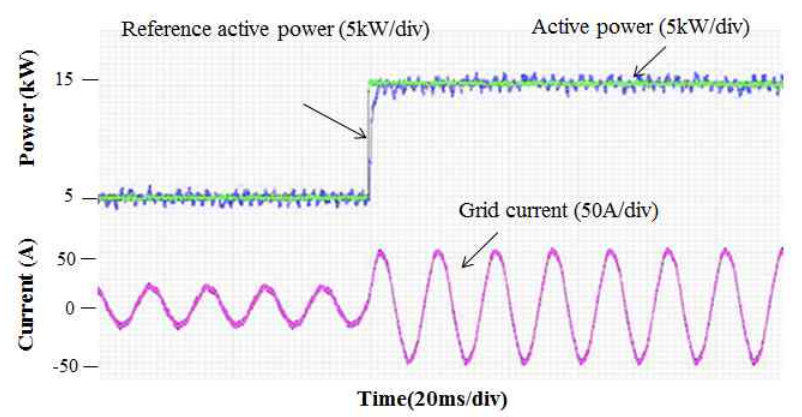

Fig. 18. Active power control by using a sliding mode: (a) active power control and (b) grid current.

We have established control by changing the reference active power have verified that the response speed of the result shown in Fig. 17 is improved compared with the response speed in Fig. 15.

\section{CONCLUSION}

This paper proposes a sliding-mode based DPC without voltage sensors to improve the performance of the controller by using variable gain values that can stabilize the system. The output voltage of the voltage equation is calculated by setting the output of the power controller as the reference voltage and realizing the DPC via the power equation that uses the flux from the voltage. The proposed DPC has a faster response speed than conventional controllers and exhibits excellent performance and feasibility.

\section{ACKNOWLEDGMENT}

This work is supported by the National Research Foundation of Korea, which is funded by the Ministry of Education, Science, and Technology (Grant No. 20110029233).

\section{REFERENCES}

[1] M. P. Kazmierkowski, R. Krishnan, and F. Blaabjerg, Control in Power Electronics, Academic Press, 2002.
[2] P. Cortés, J. Rodríguez, P. Antoniewicz, and M. Kazmierkowski, "Direct power control of an AFE using predictive control," IEEE Trans. Power Electron., Vol. 23, No. 5, pp. 2516-2523, Sep. 2008.

[3] A. Bouafia, J. Gaubert, and F. Krim, "Predictive direct power control of three-phase pulse width modulation (PWM) rectifier using space-vector modulation (SVM)," IEEE Trans. Power Electron., Vol. 25, No. 1, pp. 228-236, Jan. 2012.

[4] K. B. Lee and F. Blaabjerg, "An improved DTC-SVM method for sensorless matrix converter drives using an overmodulation and simple non-linearity compensation," IEEE Trans. Ind. Electron., Vol. 54, No. 6, pp. 3155-3166, Dec. 2007.

[5] K. B. Lee and F. Blaabjerg, "Sensorless DTC-SVM for induction motor driven by a matrix converter using a parameter estimation strategy," IEEE Trans. Ind. Electron., Vol. 55, No. 2, pp. 512-521, Feb. 2008.

[6] L. Xiao, S. Huang, L. Zheng, Q. Xu, and K. Huang, "Sliding mode SCM-DPC for grid-side converter of D-PMSG under asymmetrical faults," International Conference on Electrical Machines and Systems, pp. 1-6, Aug. 2011.

[7] V. I. Utkin, "Sliding mode control design principles and applications to electric drives," IEEE Trans. Ind. Electron., Vol. 40, No. 1, pp. 23-36, Feb. 1993.

[8] F. Hamoud, A. A. Chaghi, H. Amimeur, and E. K. Merabet, "Sliding mode control with fixed switching frequency for four-wire shunt active filter," Journal of Electrical Engineering \& Technology, Vol. 6, No. 5, pp. 647-657, Sep. 2011.

[9] H. G. Jeong, W. S. Kim, K. B. Lee, B. C. Jeong, and S. H. Song, "A sliding-mode approach to control the active and reactive powers for a DFIG in wind turbines," IEEE Power Electronics Specialists Conference, pp. 120-125, 2008.

[10] S. T. Jou, S. B. Lee, Y. B. Park, and K. B. Lee, "Direct power control of a DFIG in wind turbines to improve dynamic responses," Journal of Power Electronics, Vol. 9, No. 5, pp. 781-790, Sep. 2009.

[11] W. S. Im, J. S. Kim, J. M. Kim, D. C. Lee, and K. B. Lee, "Diagnosis methods for IGBT open switch fault applied to 3-Phase AC/DC PWM converter," Journal of Power Electronics, Vol. 12, No. 1, pp. 120-127, Jan. 2012.

[12] D. K. Chwa and K. B. Lee, "Variable structure control of the active and reactive powers for a DFIG in wind turbines," IEEE Trans. Ind. Appl., Vol. 46, No. 6, pp. 2545-2555, Nov. 2010.

[13] C. Lascu, I. Boldea, and F. Blaabjerg, "Variable-structure direct torque control-A class of fast and robust controllers for induction machine drives," IEEE Trans. Ind. Electron., Vol. 51, No. 4, pp.785-792, Aug. 2004.

[14] J. $\mathrm{Hu}$ and B. Hu, "Direct active and reactive power regulation of grid connected voltage source converters using sliding mode control approach," IEEE International Symposium on Industrial Electronics, pp. 3877-3882, July 2010.

[15] M. Malinowski, M. Jasinski, and M. P. Kazmierkowski, "Simple direct power control of three phase PWM rectifier using space vector modulation (DPC-SVM)," IEEE Trans. Ind. Electron., Vol. 51, No. 2, pp. 447-454, Apr. 2004. 


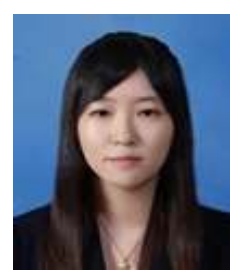

Ju-Hye Kim received her BS degree in electronic engineering from Ajou University, Suwon, Korea, in 2012. She is currently working toward an MS degree in electronic engineering at Ajou University. Her research interests include power conversion and grid-connected systems.

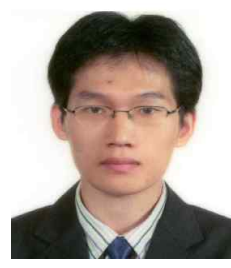

Sung-Tak Jou received his BS degree in electronic engineering from Ajou University, Suwon, Korea, in 2005. He is currently working toward his $\mathrm{PhD}$ in electronic engineering at Ajou University. His research interests include power conversion and electric machine drives.

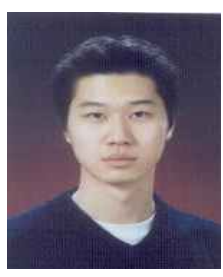

Dae-Keun Choi received his BS and MS degrees in electronic engineering from Ajou University, Suwon, Korea, in 2009 and 2011, respectively. He is currently working toward his $\mathrm{PhD}$ at Ajou University. His research interests include power conversion and grid-connected systems.

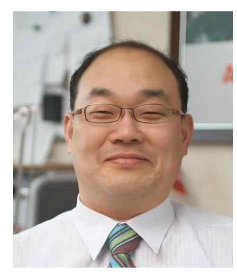

Kyo-Beum Lee received his BS and MS degrees in electrical and electronic engineering from Ajou University, Suwon, Korea, in 1997 and 1999, respectively. He received his $\mathrm{PhD}$ in electrical engineering from Korea University in 2003. From 2003 to 2006, he worked with the Institute of Energy Technology, Aalborg University, Aalborg, Denmark, from 2003 to 2006. From 2006 to 2007, he worked with the Division of Electronics and Information Engineering, Chonbuk National University, Jeonju, Korea. In 2007, he joined the School of Electrical and Computer Engineering at Ajou University, Suwon, Korea. He is an associate editor of IEEE Transactions on Power Electronics, IEEE Transactions on Industrial Electronics, and Journal of Power Electronics. His research interests include electric machine drives and wind power generation. 